\title{
Differential recruitment of annelids onto tidal elevations in an estuarine mud flat
}

\author{
Hwey-Lian Hsieh ${ }^{1, *}$, Chi-Feng Hsu ${ }^{1,2}$ \\ ${ }^{1}$ Institute of Zoology, Academia Sinica, Taipei, Taiwan 115, Republic of China \\ ${ }^{2}$ Institute of Fisheries Science, National Taiwan University, Taipei, Taiwan 106, Republic of China
}

\begin{abstract}
The recruitment of an annelid community was examined on 2 tidal elevations in 2 kinds of sediments along an inclined intertidal mud flat in an estuary in northern Taiwan. Recruitment onto defaunated and ambient intact sediments (control) in both low and high tidal zones was followed weekly from 3 April to 1 May 1996. The overall density of recruits in the defaunated sediments reached the level of the control sediments within $3 \mathrm{wk}$ in the low tidal zone, whereas in the high tidal zone the density of recruits did not reach the control level during the study period. Two polychaete species and 1 oligochaete species were the major recruits, and each exhibited a different recruitment mode and rate. The spionid Prionospio japonica and the oligochaete Doliodrilus tener were among the most rapid recruits. $P$. japonica simultaneously exhibited 2 recruitment modes, larval settlement and postlarval transportation, and its recruit density in the defaunated sediments in the low tidal zone reached the level of the control within $1 \mathrm{wk}$. D. tener recruited predominately by means of juvenile migration. In general, recruitment by settling larvae occurred at discrete intervals, whereas that by postlarvae or juveniles appeared to be continuous. The densities of $P$. japonica and of $D$. tener exhibited a zonation pattern wherein density increased along a down-shore gradient. The sedimentary characteristics also exhibited a similar zonation pattern, wherein the sediment particles became smaller and silt/clay content increased in the low tidal zone. This coupled phenomenon suggests that tidal action has a strong influence on the recruitment of $P$. japonica and $D$. tener. These recruits are passively entrapped in the low tidal zone due to the depositional conditions created by slow flows. However, the tidal zonation of the capitellid Capitella sp. showed an opposite trend, with greater recruitment in the high tidal zone, indicating that the recruitment of Capitella sp. possessed an active component. $D$. tener recruited mostly into the low tidal zone, but a small, significant proportion of the recruitment occurred in the high tidal zone. Capitella sp. and D. tener are subsurface burrowers, and thus, to some extent, their recruitment is less controlled by tidal action. Overall, the recruitment of this annelid community is influenced by both physical and biological controls.
\end{abstract}

KEY WORDS: Annelid recruitment - Tidal elevation - Defaunation · Estuary

\section{INTRODUCTION}

The recruitment events of marine sedimentary benthic communities involve a series of processes that vary in time and space and act simultaneously at different biological and physical scales (Underwood \& Fairweather 1989, Rodriguez et al. 1993, Palmer et al. 1996). The integration of these various processes is critical in the establishment and the continuity of adult communities.

\footnotetext{
·E-mail:zoh]@ccvax.sinica.edu.tw
}

Within biological scales, recruitment involves 4 major components: forms of recruits (e.g. Smith \& Brumsickle 1989), availability of recruits (e.g. Underwood \& Fairweather 1989), capabilities of habitat selection (e.g. Rodriguez et al. 1993, Woodin et al. 1995), and responses to established adult infauna (e.g. Gallagher et al. 1983, McCann \& Levin 1989, Krager \& Woodin 1993). Within physical scales, the potential influence of hydrodynamics on recruitment has been extensively documented (e.g. Butman 1987, Snelgrove et al. 1993). Depositional conditions formed under certain flow regimes can serve as a retention system that concentrates detritus and planktonic larvae (e.g. Brown 1982, 
Jumars \& Nowell 1984, Snelgrove 1994). Under such passive entrainment, habitat selection, recruit-adult interactions and postlarval transportation are often mediated through flows (e.g. Eckman 1983, Grant 1983, Ertman \& Jumars 1988, Abelson \& Denny 1997).

Macroinfauna on sedimentary tidal flats often exhibit zonal distribution between tidemarks. The zonation may be formed first during the recruitment stage and then changed during the post-recruitment stage in which physical and biological processes act sequentially (e.g. passive settlement vs active migration after settlement) (Tamaki 1985, Armonies \& HellwigArmonies 1992, Glemarec \& Guillou 1996). Moreover, the zonation may not be parallel to the tidal elevation but rather correlate with sedimentary characteristics along the shore, revealing the importance of hydrodynamics in the control of zonal formation (e.g. Beukema 1976, Brown 1982). In zones with movable sediments due to tidal flows of high energy (Grant 1981), such as in ripple crests and high tidal areas, recruitment is often blocked and active burrowers are usually the only recruits able to survive (Brown 1982). The distribution of species that can retreat or burrow into deeper sediment layers is quite insensitive to flow structure, and thus lacks a zonal pattern along the gradient of tidal elevation (e.g. oligochaetes and Capitella spp., Zühlke \& Reise 1994).

Few studies examining the factors controlling recruitment events have been conducted in intertidal mud flat habitats. Based on the analyses described above, however, we hypothesized that tidal action, through the alteration of sedimentary characteristics, is the primary regulatory force in the development of the zonal pattern of recruitment found in intertidal areas. Biological processes, we surmised, would only be important in some cases. We tested this hypothesis by conducting an experiment in the intertidal mud flat of the Tanshui estuary, northern Taiwan, where the infaunal community is dominated by annelids (Hsieh 1995, Erséus \& Hsieh 1997). The population densities of these annelids increase along a down-shore gradient; however, the zonation pattern varies with different species and with the life stages of a given species (Hsieh unpubl. data)

In order to examine the hypothesis mentioned above, the purpose of the present study is to demonstrate the effects of tidal elevation and defaunation on annelid recruitment. By applying small-scale defaunation at 2 tidal levels and then examining the subsequent changes both in the recruit community and in abiotic factors, the experiments are designed to observe: (1) what recruitment modes, rates and timing the recruits exhibit; (2) how tidal action affects recruitment by altering sedimentary characteristics; and (3) whether defaunation affects recruitment.

\section{MATERIALS AND METHODS}

Study area. The study area is located in the intertidal mud flat in the Tanshui estuary, northern Taiwan. The distance between the mean high and mean low tidal zones is approximately $35 \mathrm{~m}$ with an inclination of $1: 16$. The mud flat surface is smooth. The grain sizes range from mud to very fine sand 0.06 to $0.14 \mathrm{~mm}$ median particle sizes, Hsieh 1995). Water salinities vary from 0 to $33 \%$ (Hsieh 1997). The high and low tidal zones are submerged for 12 and $18 \mathrm{~h}$, respectively.

Potential recruits. Most of the polychaetes in this estuary reproduce semi-continuously and have a long breeding season. The spionid (e.g. Prionospio japonica, Polydora sp. and Pseudopolydora sp.) and the sabellid (Laonome albicingillum) larvae constitute the majority of the macroinfaunal larval community and occur almost year round with peaks in spring (March to May) and fall (October to December) (Chang 1992, Hsieh 1995, 1997). Juvenile P. japonica can be found in the planktons; however, this is not the case for the other species.

Definition of recruits. In the present study, recruit is used as a collective term for larvae, postlarvae, juveniles or even adults that perform as supply individuals. A juvenile is distinguished from a postlarva as some species lack a planktonic larval stage. Recruiting individuals can be identified by size, measured by the number of segments or setigers. The planktonic larvae of the sabellid Laonome albicingillum become competent and settled at 3 to 5 setigers; those of the nereid Neanthes glandicincta at 4 to 5 setigers and those of the spionid Prionospio japonica at 12 to 15 setigers (Hsieh 1997, unpubl data). While capitellids brood their eggs, their larvae are rarely found in plankton despite the frequent plankton tows conducted in this estuary over several years (authors' pers. obs.), suggesting that the offspring of the capitellids studied are probably demersal forms. The oligochaete Doliodrilus tener does not reproduce asexually. Regarding Capitella sp. and $D$. tener, since little reproductive data is available, the specific minimum size at maturation is used as a reference to determine the stages of recruiting individuals. Capitella sp. has a minimum mature size ranging from 40 to 45 setigers (Hsieh unpubl. data), whereas that of $D$. tener ranges from 30 to 33 segments (Erséus 1984).

Determination of sampling depth. A preliminary study was conducted to determine sampling depth in August 1995. A total of 15 sediment cores were taken with a PVC corer of $3.6 \mathrm{~cm}$ inner diameter. Sediment core samples were separated into 2 subsamples according to the depth below the surface, $0-1 \mathrm{~cm}$ and $1-2 \mathrm{~cm}$, respectively. Subsequently, subsamples were treated by adding $0.2 \% 2$-phenoxyethanol and $10 \%$ formalin 
with Rose Bengal. The infauna retained on a $62 \mu \mathrm{m}$ mesh screen were identified to species level and counted. Fragmented individuals, which were often adults, were not counted.

Nearly $80 \%$ of the total annelid abundance occurred in the top $1 \mathrm{~cm}$ layer, and juvenile Laonome albicingillum was distributed only in the top $1 \mathrm{~cm}$ (Table 1). Only $49 \%$ of Doliodrilus tener individuals occurred in the top $1 \mathrm{~cm}$, but the majority of these individuals were smaller than 35 segments, indicating that $D$. tener living in the top $1 \mathrm{~cm}$ layer were juveniles. Therefore, the top $1 \mathrm{~cm}$ layer was chosen as the sampling depth.

Experimental design and sampling schemes. The effects of tidal elevation and defaunation on the recruitment were examined in 2 tidal zones and in sediments with or without defaunation (i.e. sediments with or without intact ambient substrata). The high and low tidal zones were taken to be at a distance of $6 \mathrm{~m}$ above and below the mean middle tidal zone, respectively. In each zone, 3 defaunated plots and 3 control sediments were deployed. The defaunated plots containing defaunated sediments were placed at $10 \mathrm{~m}$ intervals, whereas the control sediments were located in intact ambient substrates $5 \mathrm{~m}$ away from the defaunated plots. Each defaunated plot was $60 \mathrm{~cm}$ in length by $60 \mathrm{~cm}$ in width by $5 \mathrm{~cm}$ in depth and was enclosed by a $0.3 \mathrm{~mm}$ mesh screen to prevent the entrance of large infauna through the bottom and sides, while still allowing free movement of pore water. The surface of the plots was flushed freely with the ambient sediments and the edges of the plots were buried in the sediments in order to minimize possible alterations of bottom flows. Defaunated sediments were prepared by freezing sediments collected from high, middle and low tidal zones in the study area at $-70^{\circ} \mathrm{C}$ for $7 \mathrm{~d}$ and then defreezing. This process was then repeated once again. These azoic sediments were thoroughly mixed before use. The treatment procedure of defaunation may also destroy the chemical and microbiological structure of the sediments.

Sampling was conducted 5 times on a weekly basis from 3 April 1996 to 1 May 1996. Core samples from the sediment treatments were collected according to a random procedure without replacement. On each sampling day, within each defaunated plot, 3 biotic cores and 1 set of abiotic cores were taken. Within each control sediment, 1 biotic core was also taken. However, for the control sediments in each given tidal zone, only 1 set of abiotic cores was collected. Therefore, at each sampling time, 18 biotic samples ( 3 cores $\times 3$ defaunated plots $\times 2$ tidal zones) and 6 sets of abiotic samples ( 1 set $\times 3$ plots $\times 2$ tidal zones) were collected from the defaunated plots. For the control sediments, 6 biotic samples $(1$ core $\times 3$ control sediments $\times 2$ tidal zones) and 2 sets of abiotic samples ( 1 set $\times 2$ tidal zones) were collected. For the biotic samples, the sampling corers, the processes and the measurements used were the same as those described above in the preliminary study. For the abiotic samples, a larger corer $(4.2 \mathrm{~cm}$ in diameter) was used. Each set of abiotic samples contained 3 sediment cores; 1 was preserved in $5 \%$ formalin for granulometric analysis, whereas the other 2 were refrigerated at about $12^{\circ} \mathrm{C}$ soon after the collection. In the laboratory, the second core was used for measuring the water content and the third one was kept at $-70^{\circ} \mathrm{C}$ for measurement of total organic carbon (TOC) content.

Measurements of abiotic properties of sediment. The granulometry of the sediment was determined following Buchanan \& Kain (1971) and Hsieh (1995). The water content of the sediment was measured as the percent weight loss after oven-drying at $60^{\circ} \mathrm{C}$ for $48 \mathrm{~h}$. The TOC content of the sediment, expressed as percent dry weight, was determined by cryo-drying the sediment, mixing it thoroughly and then adding about $2 \mathrm{ml} 1 \mathrm{~N} \mathrm{HCl}$ to remove inorganic carbon. The TOC content was then measured by using an element analyzer (Horiba EMIA-510).

Statistics and analyses. The sedimentary properties and the population densities of each recruit species were compared between the defaunated and the control sediments in the low and the high tidal zones using Wilcoxon 2-sample tests and/or ANOVA (Sokal \& Rohlf 1981). The main effects of tidal elevation and defaunation on recruitment were examined using 2-way ANOVAs. The 2-way nonparametric extended KruskalWallis test was used (Zar 1984) if the variances among treatments were still heterogeneous even after the data was transformed. All tests were set at a significant level of $5 \%$.

Table 1. Vertical distribution of annelid juveniles in the upper layers of the sediments in the mud flat of the Tanshui estuary, Taiwan. Density is expressed as mean number of individuals per $10.3 \mathrm{~cm}^{2}(n=15)$

\begin{tabular}{|c|c|c|c|c|c|c|c|c|c|c|}
\hline \multirow[t]{2}{*}{ Depth } & \multicolumn{2}{|c|}{ Capitella sp. } & \multicolumn{2}{|c|}{ Laonome albicingillum } & \multicolumn{2}{|c|}{ Neanthes glandicincta } & \multicolumn{2}{|c|}{ Doliodrilus tener } & \multicolumn{2}{|c|}{ Total } \\
\hline & Density & $\%$ & Density & $\%$ & Density & $\%$ & Density & $\%$ & Density & $\%$ \\
\hline $0-1 \mathrm{~cm}$ & 8.33 & 82.2 & 4.60 & 100.0 & 2.20 & 84.6 & 2.53 & 48.6 & 18.00 & 78.3 \\
\hline $1-2 \mathrm{~cm}$ & 1.80 & 17.8 & 0.00 & 0.0 & 0.40 & 15.4 & 2.67 & 51.4 & 5.00 & 21.7 \\
\hline Sum & 10.13 & 100.0 & 4.60 & 100.0 & 2.60 & 100.0 & 5.20 & 100.0 & 23.00 & 100.0 \\
\hline
\end{tabular}


Analyses of the size frequency distribution of recruits were performed weekly to determine the mode of recruitment of each species. However, at Week 4 the recruits of Prionospio japonica and Doliodrilus tener in the defaunated plots in the low tidal zone were so abundant that only $1 / 3$ of the individuals were randomly chosen for the analyses.

\section{RESULTS}

\section{Abiotic properties of sediment}

At the commencement of the study, the granulometry and the chemical properties of sediments were similar to one another among all defaunated sediments (Fig. 1). As time proceeded, the abiotic properties of the defaunated and the control sediments gradually became similar to each other (all Wilcoxon 2-sample tests having $p>0.05$ ). By contrast, except the water content, the abiotic characteristics between the 2 different tidal zones gradually became dissimilar. In the low tidal zone, the grain sizes decreased from

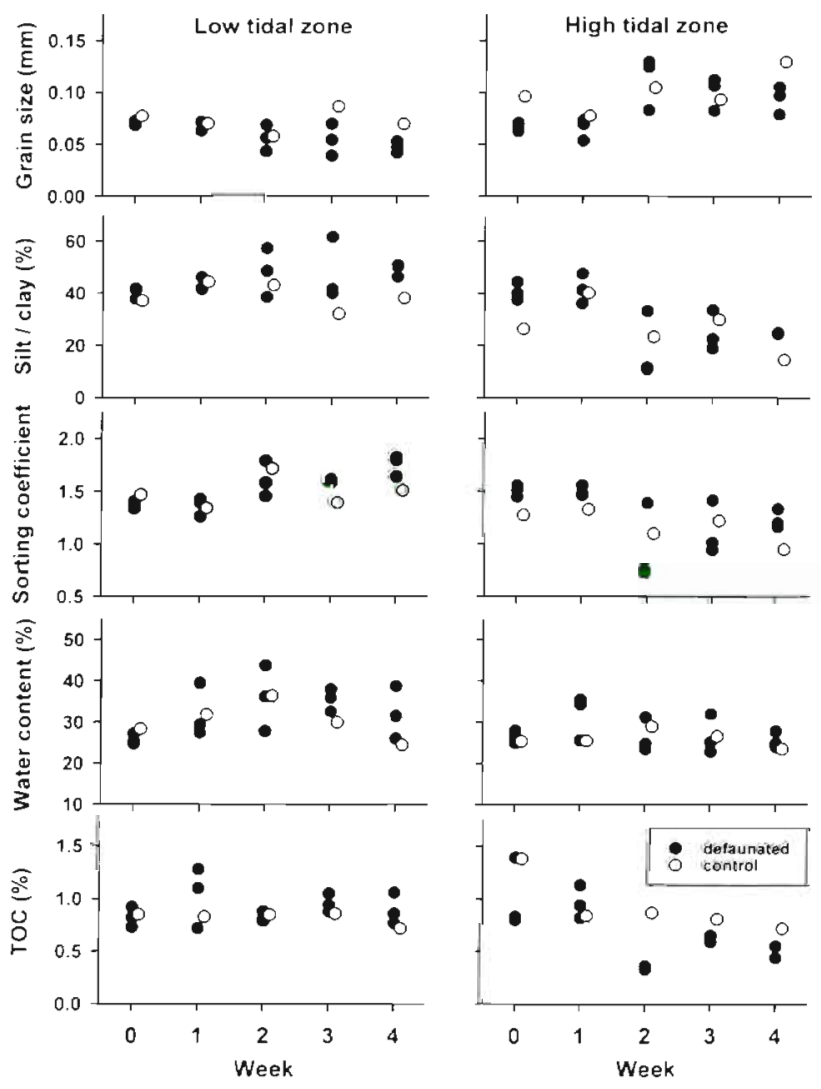

Fig. 1. Changes in sedimentary properties in the low and high tidal zones in the mud flat of the Tanshui estuary during the 4 wk study period (April to May 1996). For clarity, data points for the control sediments are of fset. TOC: total organic carbon
$0.07-0.08 \mathrm{~mm}$ in Week 0 to $0.04-0.06 \mathrm{~mm}$ in Week 4 whereas in the high tidal zone, the grain sizes increased from $0.06-0.10 \mathrm{~mm}$ in Week 0 to $0.08-0.13 \mathrm{~mm}$ in Week 4 . Similarly, but in an opposite sense, the silt and clay content, the sorting coefficient and the organic content of the sediment in the low tidal zone increased with time, whereas the reverse trend was found in the high tidal zone (Fig. 1). At the end of Week 4 , the sediments in the low tidal zone contained smaller grains, more silts and clays (low vs high tide zone, $38-51$ vs $15-25 \%)$, a lower degree of sorting $(1.5-1.8$ vs $0.9-1.3)$ and higher organic content $(0.7-1.1$ vs $0.4-0.7 \%)$ than those in the high tidal zone (all tests with $p<0.05$ ).

\section{Species composition}

Two polychaete species and 1 oligochaete species appeared as the major recruits, namely the spionid Prionospio japonica Okuda, the capitellid Capitella sp., and the tubificid oligochaete Doliodrilus tener Erséus. $P$. japonica and D. tener comprised 11.5 and $78.5 \%$ of the total recruit abundance, respectively. Another 2 polychaete species, the sabellid Laonome albicingillum Hsieh and the nereid Neanthes glandicincta (Southern), occurred only rarely.

\section{Recruit size and recruitment mode}

The size of Prionospio japonica ranged from 8 to 50 setigers. However, the size frequency peaked at the smallest size group of 8 to 17 setigers (Fig. 2). This was comparable with that of a settling larva (12 to 15 setigers), indicating that the recruitment of $P$. japonica was by means of larval settling from the water column. Moreover, the larval settlement occurred twice separated by a 4 wh interval, one time during Week 0 and the other during Week 4. This pattern was most obvious in the control sediments in the low tidal zone (Fig. 2). In Week 0, newly settled individuals were collected in the control sediments but not in the defaunated sediments, which had just been installed in the study sites, indicating that the larval settlement during Week 0 occurred shortly before the first sampling (Fig. 2). In addition, in the defaunated sediments in the low tidal zone from Week 1 through Week 3 , there were still many recruits present. These individuals had sizes larger than that of a settling larva, indicating that they arrived at the mud flat by means of postlarval transportation.

Doliodrilus tener had body sizes ranging from 8 to 62 segments, with an unimodal size distribution throughout the 4 wk period (Fig. 3). The size frequency peaked 
Low tidal zone

P. japonica

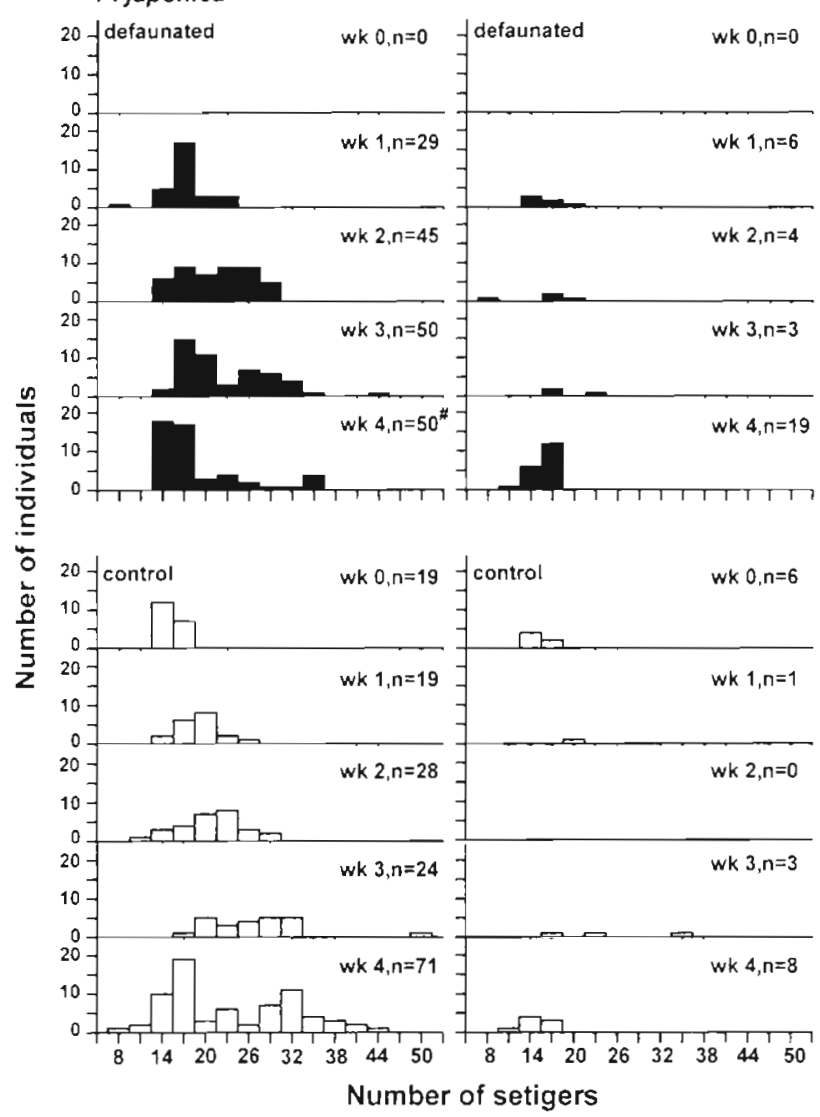

Fig. 2. Prionospio japonica. Size frequency distribution of the spionid recruited into the control and defaunated sediments in the low and high tidal zones during the study period. \#: only $1 / 3$ of the recruit individuals were measured

at 20 segments, which was smaller than the size of an adult ( 30 to 33 segments), indicating that juveniles were the major recruiting group for this species.

The recruit size of Capitella sp. ranged from 12 to 29 setigers with a peak at 13 to 16 setigers. This size was smaller than the size of an adult (40 to 45 setigers), suggesting that the recruitment of this species was performed by larval settlement.

\section{Rate of recruitment}

Over the study period, there were net increases in the recruitment onto both defaunated and ambient control sediments in both low and high tidal zones. In the defaunated sediments in the low tidal zone, the recruit density increased markedly and steadily to the level of the control sediments within $3 \mathrm{wk}$ (from 0 to 74 ind. $/ 10.3 \mathrm{~cm}^{2}$ ) (Fig. 4). In contrast, in the defaunated sediments in the high tidal zone, the recruitment rate was much slower and the recruit density did not reach the level of the control sediments by the time the study was terminated (from 0 to $15.8 \mathrm{ind} . / 10.3 \mathrm{~cm}^{2}$ in $4 \mathrm{wk}$ ) (Fig, 4). In the control sediments, the recruit densities in both zones also increased with time (from 75 to 105 ind. $/ 10.3 \mathrm{~cm}^{2}$ in the low tidal zone and from 12 to 77 in the high tidal zone) (Fig. 4).

Specifically, Prionospio japonica and Doliodrilus tener exhibited more rapid and prominent recruitment than Capitella sp. The abundance of both $P$. japonica and $D$. tener in the defaunated sediments in the low tidal zone increased steadily throughout the 4 wk period and reached the same level as in the control sediments by Weeks 1 and 3, respectively (Fig. 5). In addition, in the control sediments in the high tidal zone, the recruitment of $D$. tener was greater than that of $P$. japonica (Fig. 5). In contrast, the recruitment of Capitella sp. was minimal until Week 4 , by which time the recruitment became detectable in the control sediments, gaining an average of 45 recruits $/ 10.3 \mathrm{~cm}^{2}$ in the control sediments in the high tidal zone (Fig. 5).

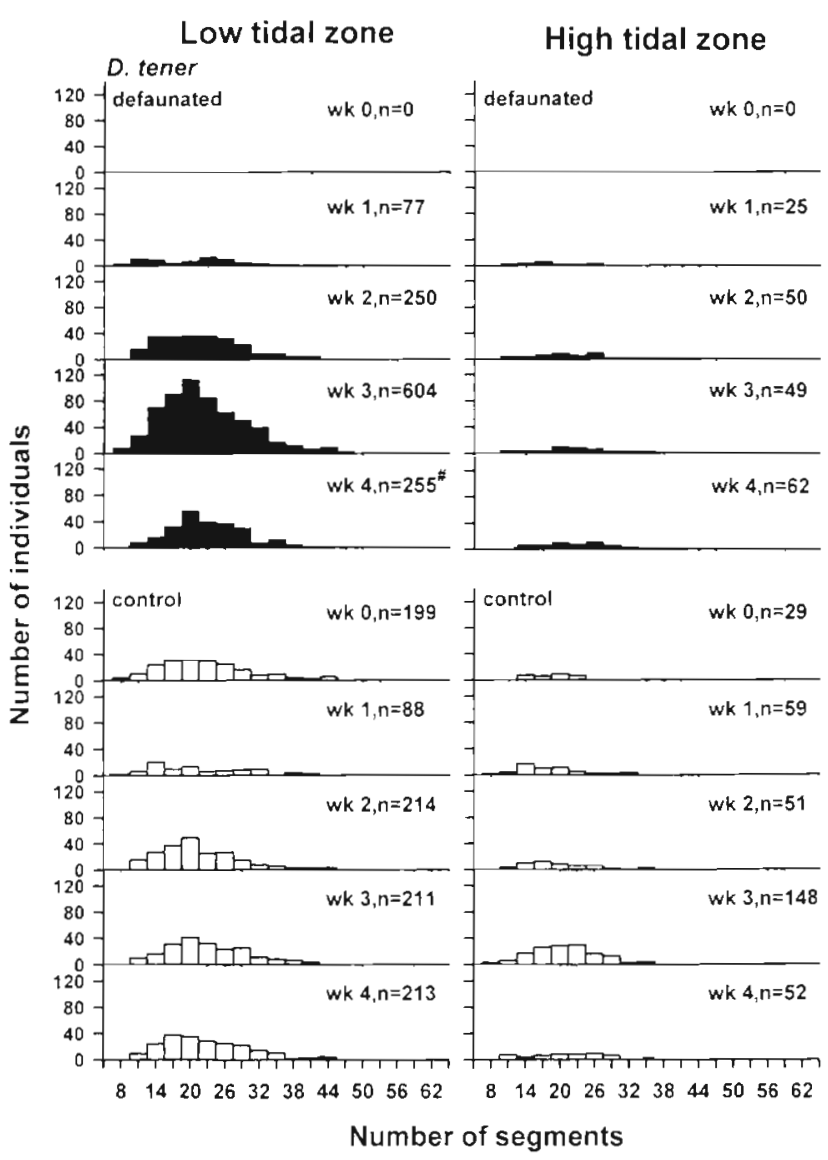

Fig. 3. Doliodrilus tener. Size frequency distribution of the oligochaete recruited into the control and defaunated sediments in the low and high tidal zones during the study period. $\#$ : only $1 / 3$ of the recruit individuals were measured 

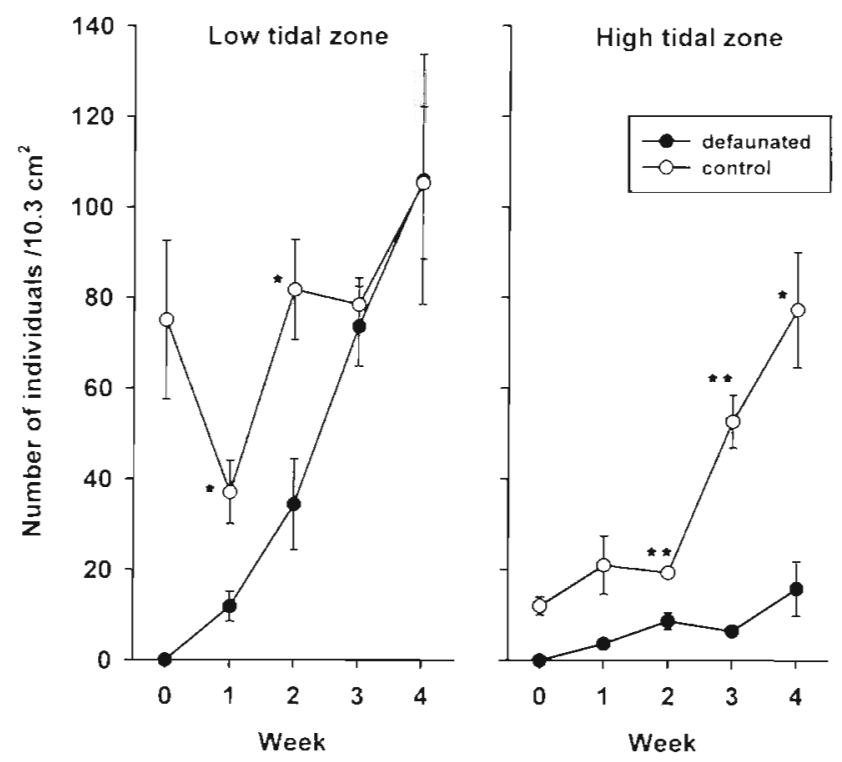

Fig. 4. Density changes (mean $\pm \mathrm{SE}$ ) of the whole recruit community in the control and defaunated sediments in the low and high tidal zones during the study period. Significant differences in the densities between the control and defaunated sediments are indicated. No comparison was performed in Week $0 .{ }^{\star} \mathrm{p}<0.05,{ }^{\star \star *} \mathrm{p}<0.01$

\section{Effects of tidal elevation and defaunation on recruitment}

In the defaunated sediments adult-sized infauna were found only occasionally, comprising approximately $0.5 \%$ of the total recruit abundance over the 4 wk period. Thus, the effects of adult entrance were negligible.

The 2-way ANOVA and nonparametric analyses of the responses of the recruits to different sediment treatments revealed that recruitment was affected by tidal elevation and defauration. However, the responses varied with time, type of effect and species (Table 2). In general, the recruitment was affected more by tidal elevation than by defaunation. In the cases exhibiting the effects of tidal elevation, recruitment was more intense in the low tidal zone than in the high tidal zone ( 7 vs 1 case in a total of 8 cases) (Table 2). When the recruitment was influenced by defaunation, the recruit abundance was greater in the control than in the defaunated sediments ( 5 out of 5 cases) (Table 2), suggesting that the intact ambient substrata has positive effects on the recruitment.

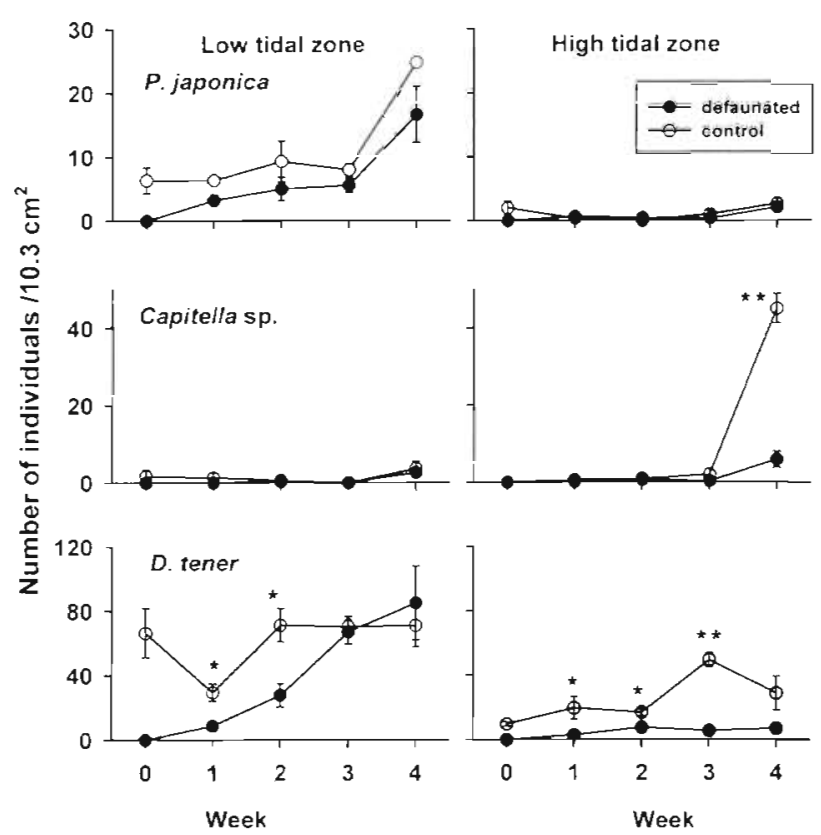

Fig. 5. Prionospio japonica, Capitella sp., and Doliodrilus tener. Density changes (mean $\pm \mathrm{SE}$ ) of each annelid species recruited into the control and defaunated sediments in the low and high tidal zones during the study period. Significant differences in the densities between the control and defaunated sediments are indicated. ${ }^{*} p<0.05,{ }^{* *} p<0.01$

The recruitment of Prionospio japonica, Doliodrilus tener and Capitella sp. was also affected by the interactions between the tidal elevation and the defaunation treatment. However, the F-values of the interaction terms were smaller than those of the main

Table 2. Effects of tidal elevation, defaunation and interactions of tidal elevation and defaunation on the recruitment of the annelid species in the mud flat of the Tanshui estuary. The 2-way ANOVA was performed each week, except for Week 4 for Prionospio japonica, when a 2-way nonparametric extended Kruskal-Wallis test was performed. F-values are listed. low: Low tidal zone; high: high tidal zone; cont: control seciment; def: defaunated sediment. $p<0.05$, $\because p<0.01$, ns: not significant

\begin{tabular}{|c|c|c|c|c|c|}
\hline Species & Week & $\begin{array}{l}\text { Tidal } \\
\text { effect }\end{array}$ & $\begin{array}{c}\text { Defaunation } \\
\text { effect }\end{array}$ & $\begin{array}{c}\text { Tide } x \\
\text { Defaunation }\end{array}$ & Main effects \\
\hline \multicolumn{6}{|c|}{ Prionospio japonica } \\
\hline & 1 & $51.56 \cdots$ & $5.43^{\circ}$ & $8.36^{\circ}$ & low $>$ high, cont $>$ def \\
\hline & 2 & $14.22^{\cdots}$ & ns & ns & low $>$ high \\
\hline & 3 & $58.17 \cdots$ & ns & ns & low $>$ high \\
\hline & 4 & $8.31 \cdots$ & ns & ns & low $>$ high \\
\hline \multicolumn{6}{|c|}{ Capitella sp. } \\
\hline & 1 & ns & ns & ns & \\
\hline & 2 & ns & ns & ns & \\
\hline & 3 & ns & ns & ns & \\
\hline & 4 & $89.73^{*}$ & $72.72 \cdots$ & $65.65^{\cdots}$ & high $>$ low, cont $>$ def \\
\hline \multicolumn{6}{|c|}{ Doliodrilus tener } \\
\hline & 1 & ns & $17.06^{*} \cdot$ & ns & cont $>$ def \\
\hline & 2 & $33.03^{*}$ & $16.69 *$ & $6.91^{\circ}$ & low $>$ high, cont $>$ def \\
\hline & 3 & $59.07 \cdots$ & $19.18^{*}$ & $14.29 \cdots$ & low $>$ high, cont $>$ def \\
\hline & 4 & $17.47^{*}$ & ns & ns & low $>$ high \\
\hline
\end{tabular}


factors, with only 4 out of 12 comparisons exhibiting a significant interaction effect (Table 2). This indicated that the recruitment of these 3 species was affected less by the interaction effects than by the main effects of tidal elevation or intactness of ambient substrata.

Over the $4 \mathrm{wk}$ period, the recruitment of Prionospio japonica and Doliodrilus tener was significantly greater into the low tidal zone than into the high tidal zone (Table 2). However, the recruitment of these 2 species differed in that $D$. tener was influenced more by the intactness of the sediments ( 3 out of 4 comparisons in $D$. tener vs 1 out of 4 in $P$. japonica) (Table 2). The recruitment of Capitella sp. in Week 4 was affected more by the tidal elevation and was greater in control than in the defaunated sediments in the high tidal zone (Table 2).

\section{DISCUSSION}

The results of the present study demonstrate that integrated biological and physical processes affect the recruitment of an annelid infaunal community in an estuarine mud flat. The species-specific mode, timing and rate of recruitment and sedimentary characteristics (determined by tidal action) all act together to determine the zonation distribution of this recruit community. As compared with the effects of the intactness of the substrata and biological active responses, recruitment is influenced more greatly by the effects of tidal action, as predicted in the original hypothesis.

\section{Recruitment mode and timing}

In the annelid infaunal community of the Tanshui estuary, recruitment occurs in 3 different modes, namely larval settlement, postlarval transportation, and juvenile and/or adult migration. The recruitment mode varies with species in terms of timing, intensity and frequency of episodes. In addition, more than 1 mode is exhibited within a given species, as in Prionospio japonica, which utilizes 2 very different, yet well coupled, recruitment pathways.

In Prionospio japonica, the larvae settle onto the mud flat at discrete intervals, whereas the postlarvae arrive continuously. The difference in timing between these 2 pathways can be attributed to the differences in the availability of these 2 recruiting propagules. Many polychaete species, such as semi-continuous breeders, produce planktonic larvae at rhythmic intervals in a prolonged breeding season (e.g. Daly 1978, Pearson \& Rosenberg 1978, Olive 1984, Levin 1986). Discrete settlement of larvae at every spring tide has also been recorded in the opheliid Armandia sp. (Tamaki 1985).
It is likely that, in $P$. japonica, the rhythmic release of larvae makes competent larvae available at discrete intervals but not all the time.

By contrast, the postlarvae are the individuals that have lived in substrates for various lengths of time. More importantly, if they are disturbed physically or biologically they are capable of responding rapidly by leaving their initially settled sites and searching for new sites (Woodin 1991, Woodin et al. 1995). In addition, in intertidal areas disturbances caused by tidal reworking are numerous, persistent, and at a large scale, while disturbances caused by biogenic reworking are highly episodic, and at a smaller local scale (Wilson 1981, Grant 1983, Miller \& Sternberg 1988, Krager \& Woodin 1993). The study site is located on an intertidal mud flat and contains a number of infauna, and is therefore subject to various physical and biological processes. Constantly moving tides, freshwater flows, episodic defecation from the adult Laonome albicingillum (authors' pers. obs.) and foraging of fishes (Lin \& Lee 1991) all may superimpose upon each other to act as interfering agents to the newly settled Prionospio japonica, which are quite motile (see belowj. Therefore, when the postlarvae are disturbed, their transportation tends to be continuous in terms of time.

Doliodrilus tener also possesses a continuous migration pattern. It lacks a planktonic larval stage, and juveniles migrate more frequently than adults (see Fig. 3) However, adult oligochaetes live in deeper layers, and therefore recruitment by adult migration cannot be ruled out. In addition, recruitment by individuals hatching from cocoons that are laid by gravid adults is also possible, but this pathway remains uncertain.

In Capitella sp., the present data suggests that larval settlement is one of the means of recruitment. How ever, given that the adult Capitella sp. are motile burrowers and brood their young in fragile mud tubes (authors' pers. obs.), their larvae may recruit via direct hatching from the broods that have been carried around by migratory females. This pathway is likely, since in some other capitellids larvae capable of settlement soon after hatching have been reported (e.g Snelgrove et al. 1993).

\section{Recruitment mode and rate}

As compared with Doliodrilus tener, Prionospio japonica has a faster rate of recruitment into defaunated areas, especially in the low tidal zone. The greater motility and dispersal ability of the recruit $P$. japonica may be responsible for this difference. $P$. japonica has planktotrophic larvae and the postlarvae become motile and swim into the water column when 
disturbed (authors' pers. obs.), indicating that the larvae and the postlarvae of $P$. japonica are likely to be transported in the water column by flows. Flows produced by currents, tides, waves or winds can rapidly transport planktonic larvae over considerable distances (Butman 1987, Underwood \& Fairweather 1989, Palmer et al. 1996). This type of transportation is also known as advection transportation. In addition, postlarvae in many benthic invertebrates exhibit small-scale movements (from a few centimeters to a few meters), often seen as bedload transport, while some large-scale movements, such as water-column excursions, are also not uncommon (Levin 1984, Woodin 1991, Woodin et al. 1995, Palmer et al. 1996). Advective transportation may allow $P$. japonica to achieve rapid recruitment. By contrast, $D$. tener are subsurface burrowers. Juveniles or adults do not waft away from the substrates if disturbed (authors' pers. obs.), revealing that this oligochaete species spreads mainly by lateral burrowing or crawling. Since this style of locomotion involves a series of diffusion steps, which allows advancement at only a small distance at a time (Smith \& Brumsickle 1989), D. tener thus has a slower recruitment rate.

\section{Effects of tidal elevation versus active biological component on recruitment}

In the present study, the recruit community exhibits a zonal distribution in a mud flat, which basically occurs according to the same hydrodynamic rules as revealed in sand flats (e.g. Wieser 1959, Brown 1982, Eckman 1983, Glemarec \& Guillou 1996). The underlining cause of the formation of this zonal distribution can be attributed to the differential sedimentary properties of the habitat, caused by flow regimes, to which the recruits passively respond. Trapping or deposition conditions created by slow flows very likely play an important role in enhancing the recruitment of Prionospio japonica and Doliodrilus tener onto the low tidal zones.

Alternatively, the same zonal pattern can still be formed if the recruits actively select a site containing greater silt or detritus. However, given the data of this study, this mechanism seems to be less likely. The sedimentary properties of defaunated sediments in the low and high tidal zones were indistinguishable from each other in the first 2 or $3 \mathrm{wk}$, but during the same period of time, the recruit densities between the 2 zones had already become differentiated (Figs. 1 to 4 ). This suggests that the responses of the recruits, in general, do not involve much active choice, but are mostly influenced by the depositional flow conditions.
The recruitment of Capitella sp. exhibits a trend contrary to that expected from hydrodynamically passive entrainment. The recruitment of Doliodrilus tener also has a similar tendency, but to a lesser extent (Figs. 4 \& 5). Both D. tener and Capitella sp. are active subsurface burrowers, so by moving downward and laterally they can perhaps exploit the high tidal zones, where sediment erosion occurs more frequently. In studies examining the effect of flows on recruitment, it has been found that Capitella capitata and 2 oligochaete species are capable of retreating to deeper sediment layers when sediment erosion increases (Zühlke \& Reise 1994), and several capitellid species have been found to be relatively insensitive to water motion and can escape from depressions on the sea bottom if the substrate is unsuitable (e.g. Snelgrove et al. 1993, Snelgrove 1994)

The recruit densities examined in the present study were significantly higher in sediments with smaller and poorly sorted grain particles. The densities were also relatively unaffected by the organic and water contents of sediments. Studies of other marine invertebrates have also found that the organic level of sediment has little effect on recruitment (Snelgrove 1994). A low degree of sorting indicates that grain sizes are not uniform and sediment infrastructure is more complicated. Whether this heterogeneity is indicative of suitable sites for recruitment of the annelid community under study remains speculative, however.

\section{Effects of the intactness of substrata on recruitment}

The results of the present study reveal that there are still some significant connections between the effects of tidal elevation and defaunation, indicating that the control of tidal elevation on recruitment is not complete. In addition, whenever the control sediment (sediment remaining intact) does have an effect, the effect is always positive. In particular, the intactness seems to assist Doliodrilus tener and Capitella sp. in recruiting into the high tidal zone. The presence of macroinfauna can make a habitat more suitable for recruitment by increasing the oxygenation (e.g. due to burrowing, McCann \& Levin 1989) or by increasing the influx of food particles (e.g. due to the construction of feeding pits, Jumars \& Nowell 1984). Alternatively, these recruits are offspring produced by gravid females that have been living in the high tidal zone. In addition, the relative attractiveness of the control sediments for some recruits might be due to the suitable surface microbial or chemical environment compared with that of the defaunated sediments. However, the interaction between the habitat conditions and the recruits involves a number of complicated mecha- 
nisms, in particular the recruits' habitat selection and the effects of flows (e.g. Mose 1990, Woodin 1991, Abelson \& Denny 1997). Thus, in the present study, the actual mechanisms that operate between the macroinfauna, microbial environment and chemical environment and the recruits remain speculative.

Acknowledgements. The authors thank the participants for their comments when the study work was first presented at the meeting of 'The Fu-Shiang Festschrift' to celebrate Professor Fu-Shiang Chia's retirement.

\section{LITERATURE CITED}

Abeison A, Denny M (1997) Settlement of marine organisms in flow. Annu Rev Ecol Syst 28:317-339

Armonies W. Hellwig-Armonies M (1992) Passive settlement of Macoma balthica spat on tidal flats of the Wadden. Sea and subsequent migration of juveniles. Neth J Sea Res 29(4):371-378

Beukema JJ (1976) Biomass and species richness of the macrobenthic animals living on the tidal flats of the Dutch Wadden Sea. Neth J Sea Res 10:236-261

Brown B (1982) Spatial and temporal distribution of a depositfeeding polychaete on a heterogeneous tidal flat. J Exp Mar Biol Ecol 65:213-227

Buchanan JB, Kain JM (1971) Measurement of the physical and chemical environment. In: Holme NA, McIntyre AD (eds) Methods for the study of marine benthos. IBP handbook no. 16, Blackwell Scientific Publications, Oxford, p $30-58$

Butman CA (1987) Larval settlement of soft-sediment invertebrates: the spatial scales of pattern explained by active habitat selection and the emerging role of hydrodynamical processes. Oceanogr Mar Biol Annu Rev 25:113-165

Chang WB (1992) Studies on the physio-ecology of Apocyclops royi (Copepoda). PhD dissertation, Institute of Oceanography, National Taiwan University, Taipei (in Chinese)

Daly JM (1978) The annual cycle and the short term periodicity of breeding in a Northumberland population of Spirorbis spirorbis (Polychaeta: Serpulidae). J Mar Biol Assoc UK 58:161-176

Eckman JE (1983) Hydrodynamic processes affecting benthic recruitment. Limnol Oceanogr 28(2):241-257

Erséus C (1984) The marine tubificidae (Oligochaeta) of Hong Kong and southern China. Asian Mar Biol 1:135-175

Erséus C, Hsieh HL (1997) Records of estuarine Tubificidae (Oligochaeta) from Taiwan. Species Div 2:97-104

Ertman SC, Jumars PA (1988) Effects of bivalve siphonal currents on the settlement of inert particles and larvae. J Mar Res $46: 797-813$

Gallagher ED, Jumars PA, Trueblood DD (1983) Facilitation of soft-bottom benthic succession by tube builders. Ecology 64(5): 1200-1216

Glemarec M, Guillou M (1996) recruitment and year-class segregation in response to abiotic and biotic factors. Oceanol Acta 19(3-4):409-414

Grant J (1981) Sediment transport and disturbance on an intertidal sandflat: infaunal distribution and recolonization. Mar Ecol Prog Ser 6:249-255

Grant J (1983) The relative magnitude of biological and physical sediment reworking in an intertidal community. J Mar Res 41:673-689
Hsieh HL (1995) Spatial and temporal patterns of polychaete communities in a subtropical mangrove swamp: influences of sediment and microhabitat. Mar Ecol Prog Ser $127: 157-167$

Hsieh HL (1997) Self-fertilization: a potential fertilization mode in an estuarine sabellid polychaete. Mar Ecol Prog Ser 147:143-148

Jumars PA, Nowell ARM (1984) Fluid and sediment dynamic effects on marine benthic community structure. Am Zool $24: 45-55$

Krager CD, Woodin SA (1993) Spatial persistence and sediment disturbance of an arenicolid polychaete. Limnol Oceanogr 38(3):509-520

Levin LA (1984) Life history and dispersal patterns in a dense infaunal polychaete assemblage: community structure and response to disturbance. Ecology 65(4):1185-1200

Levin LA (1986) Effects of enrichment on reproduction in the opportunistic polychaete Streblospio benedicti (Webster): a mesocosm study. Biol Bull 171:143-160

Lin K, Lee SC (1991) Feeding habits of the thornfish Terapon jarbua (Forskal) from the estuary of Tanshui River and its adjacent waters. J Fish Soc Taiwan 18(4):257-264

McCann LD, Levin LA (1989) Oligochaete influence on settlement, growth and reproduction in a surface-depositfeeding polychaete. J Exp Mar Biol Ecol 131:233-253

Miller DC, Sternberg RW (1988) Field measurements of the fluid and sediment-dynamic environment of a benthic deposit feeder. J Mar Res 46:771-796

Mose DE (1990) Recent progress in larval settlement and metamorphosis: closing the gaps between molecular biology and ecology. Bull Mar Sci 46:465-483

Olive PJW (1984) Environmental control of reproduction in polychaeta. In: Fischer A, Pfannenstiel HD (eds) Polychaete reproduction. Fortschr Zool 29:17-38

Palmer MA, Allan JD, Butman CA (1996) Dispersal as a regional process affecting the local dynamics of marine and stream benthic invertebrates. Trends Ecol Evol 11(8): $322-326$

Pearson TH, Rosenberg R (1978) Macrobenthic succession in relation to organic enrichment and pollution of the marine environment. Oceanogr Mar Biol Annu Rev 16:229-311

Rodriguez SR, Ojeda FP, Inestrosa NC (1993) Settlement of benthic marine invertebrates. Mar Ecol Prog Ser 97: $193-207$

Smith CR, Brumsickle SJ (1989) The effects of patch size and substrate isolation on colonization modes and rates in an intertidal sediment. Limnol Oceanogr 34(7): 1263-1277

Snelgrove PVR (1994) Hydrodynamic enhancement of invertebrate larval settlement in microdepositional environments: colonization tray experiments in a muddy habitat. J Exp Mar Biol Ecol 176:149-166

Snelgrove PVR, Butman CA, Grassle JP (1993) Hydrodynamic enhancement of larval settlelment in the bivalve Mulinia lateralis (Say) and the polychaete Capitella sp. I in microdepositional environments. J Exp Mar Biol Ecol 168: 71-109

Sokal RR, Rohlf FJ (1981) Biometry. WH Freeman and Co, San Francisco

Tamaki A (1985) Zonation by size in the Armandia sp. (Polychaeta: Ophelidae) population on an intertidal sand flat. Mar Ecol Prog Ser 27:123-133

Underwood AJ, Fairweather PG (1989) Supply-side ecology and benthic marine assemblages. Trends Ecol Evol 4(1): $16-20$

Wieser W (1959) The effect of grain size on the distribution of small invertebrates inhabiting the beaches of Puget Sound. Limnol Oceanogr 4:181-194 
Wilson WH (1981) Sediment-mediated interactions in a densely populated infaunal assemblage: the effects of the polychaete Abarenicola pacifica. J Mar Res 39:735-748

Woodin SA (1991) Recruitment of infauna: positive or negative cues? Ann Zool 31:797-807

Woodin SA, Lindsay SM, Wethey DS (1995) Process-specific

Editorial responsibility: Otto Kinne (Editor),

Oldendorf/Luhe, Germany recruitment cues in marine sedimentary systems. Biol Bull $189: 49-58$

Zar JH (1984) Biostatistical analysis. Prentice-Hall, Inc, Englewood Cliffs, NJ

Zühlke R, Reise K (1994) Response of macrofauna to drifting tidal sediments. Helgol Meeresunters 48:277-289

Submitted: May 4, 1998; Accepted: September 29, 1998

Proofs received from author(s): January 22, 1998 